\title{
Cooperative Collection Building: A Response to Gerald Beasley
}

I WOULD LIKE to begin by disputing emphatically Gerald Beasley's contention that librarians never become rich and famous. Sir Anthony Panizzi (1797-1879), Principal Librarian of the British Museum, was both, and so was Jorge Luis Borges (18991986), Director of the National Library in Buenos Aires. Well, perhaps Panizzi was not exactly a celebrity, and perhaps the source of Borges's fame and riches was not his role as the National Librarian of Argentina. But what about the Abbé Rive, librarian to the Duc de la Vallière? He was infamous, if not famous, for being one of the most irascible men in educated Europe, and the posthumous sale of his books in Marseilles in 1793 suggests - if the catalogue is a reliable measure — that he had no little money to spend on books, though his employer, naturally, had rather more. It is admittedly a small point, but respondents were invented to keep authors honest and to correct gently their perceptible divagations from absolute truth. So please forgive me, and by way of recompense, let me prophesy that Gerald's observation about Hollinger boxes looking as though they were in a witness protection program is destined to be quoted many times in the future.

Although Gerald has mostly chosen to emphasize the differences among libraries, archives, and museums - a wise and perhaps inevitable choice in some ways-I would like to begin by reminding us of their similarities. All three types of institutions acquire cultural artifacts with the common goals of preserving them and making them available for aesthetic and educational or research purposes. Obviously, the quotient of pedagogy versus pleasure varies enormously with the types of objects at issue. Probably only an archivist can be stimulated to any machinerecordable level by a carbon draft of a typed speech by Gerald Ford. Likewise, the teaching value of a collection of hundreds of editions of Owen Meredith's verse novel Lucille would be hard for most to fathom.

Moreover, each of the three types of institutions normally owns many, if not thousands, of the objects-in-trade that are more characteristically associated with 
the others. What major library does not include paintings, drawings, prints, and archival collections? What museum does not at least have its own archives, if not others, as well as illustrated books, auction catalogues, and other items? And even defiantly archives-focused places, like the Archive of the Americas in Spain or the Archives Nationales in Paris, own manuscript codices and some printed books, as well as more art-like objects such as maps, botanical drawings, and the like. Gerald Beasley, in an early communication to me, spoke of the Venn-diagram way in which the institutional types cross over. He was trying to make the point that there is common ground in library, museum, and archives collecting, but not necessarily so much as to be statistically significant. He is probably right at a macro level, but the shared territory is certainly worth commenting on.

In the 1920s, Gerhard Lomer, then the new University Librarian and Dean of the Library School at McGill University in Montreal, started to buy museum artifacts. He bought cuneiform tablets, Greek papyri, Egyptian antiquities, palm-leaf books, a horn book or two, bookbinding tools, and so on. His goal was to create within the library a Museum of the Book. He meant this not in the sense that Gerald used it - that is, a sort of semiprivate ward to which unused books are committed for long-term care when their digital surrogates start to run the family business—but rather in a literal sense. He wanted students to be able to see the tangible evidence of the history of writing and printing - evidence that is also, of course, encoded in every single book in library collections from the 42-line Bible forward, but that also survives in a larger variety of media long predating the invention of movable type. Although the project never materialized, and the objects acquired found their way thirty years later into the McGill Rare Book Department's "realia" collection (including, ironically, many forgeries among them), nevertheless the principle of expanding a library's main collecting mandate in a direction that handsomely and usefully enlarges its pedagogical function surely remains admirable. There was a time, too-might it still be the case? - when Canadian archivists liked to talk about "total archives": collections that contained not only written documents but also audiotapes, records, drawings, books, computer disks, prints, and even odd bits and pieces of a life lived, such as a pair of shoes (the poet Bill Bissett's running shoes are, I believe, at York University Archives in Toronto) or an unopened package of condoms (reliably reported to be among the novelist Peter Such's papers at McMaster University’s Research Collections Division in Hamilton, Ontario).

Gerald's notion of crossover, therefore, strikes me as somewhat more useful than it does him. I regard it as standard operating procedure, in a sense, and I think that it is suggestive of ways in which libraries, archives, and museums located in an urban space can cooperate, share, and develop in mutually useful ways when collections are at issue. I believe this to be a general and desirable principle, even though some- 
times things do end up in odd places — stuffed birds, for instance, in a library, or a dentist's chair in an archive. All of us could proffer many other exempla.

I doubt that anyone but a bookseller can object to the tenet, to which I carefully adhere, that for a majority of old books, one copy within a reasonably drawn geographical area is probably enough. Why duplicate? In my own situation, with the Huntington Library, the Getty Research Institute, UCLA, and the University of Southern California Library all within roughly a half hour's drive, I always check the holdings of my sister institutions before I consider acquiring anything of any serious expense, and rarely proceed with the purchase if the book is already in town, so to speak.

I do, however, recognize the limitations of this principle. Peter Howard, the Berkeley bookseller, has termed it "ringing" in the auction world sense, though that seems too harsh by half. Clearly, in a smaller urban center than mine it would have its limitations. And equally clearly, there are times when it makes sense for more than one library to own something that is crucial to the collections. It can also be convenient. When I wanted to borrow the Getty's copy of that wonderful book on the Sicilian volcanoes, Campi Phlegraei (1776), for my exhibition The World from Here: Treasures of the Great Libraries of Los Angeles, and discovered that it was already destined for another show, I went to the Huntington. Alas, their copy was in bits being restored and was therefore not available. But the copy at the Mudd Library at Pomona College was available, and so we borrowed it. Three copies of such a famous and valuable book in close proximity comprise an embarras de richesses, but I was glad for the duplication in this case. When we were putting together the exhibition, the Huntington's Gutenberg Bible was unavailable, so Susan Allen at the Getty Research Institute had the bright idea of bringing together every Gutenberg leaf in the County of Los Angeles and showing them as a lot. I bet there are enough leaves around to represent a good chunk of the book. Although we did not pursue the idea, the richness of multiple holdings would have made it possible.

If such a geographical approach to collection building is to work, it ought to be large-scale and cooperative. And, if so, then it seems to me that there is no reason why it should not extend beyond libraries and archives to include museum collections. I deeply share Gerald's sentiments when it comes to libraries focusing on the acquisition of rare books and manuscripts. Yet I fear that this wholly admirable response to the artifacts of printing and writing can become indefensible when pushed to the limits of selfishness and rapine. We librarians all want great stuff in our institutions - so much so that at times we may abandon rational principles of collecting. Objects that come our way, as gifts or even as purchases, sometimes make more sense elsewhere, but our professional culture generally and our institu- 
tional devotion specifically can dissuade us from logic and propel us toward blind entrepreneurship. We need to see the "collection" from a much broader viewpoint than our own situation. This is a necessary beginning point for greater cooperation. The end point, I believe, will be to establish more rich and varied collections than one institution, or institutional type, could ever accumulate on its own. And while readers or visitors or scholars may have to learn to sit in more than one reading room or to pay entrance fees at more than one temple of the muses to see all the Cruickshanks in town, it is still better to have all of them available than not because money and time were spent instead on duplicating Dürers or Oudrys. The Caltech Institute Archives in Pasadena recently acquired one of the earliest books to deal with earthquakes, a small book on a minor quake in Mainz written by a priest whose name - and this was not made up by the Religious Tract Society-was Father Nausea. It was published in 1531, and one might make a strong case for such a book being given to a larger place with more early books-UCLA or the Huntington, for example. Yet how appropriate that such a book is kept at an institution that does research on seismic events. In any case, one is glad to have it "around."

If institutions of different hues are to work in each other's worlds more closely or cooperatively, the cultures of each need to be understood better, by themselves and by others. Librarians and archivists legendarily work badly together, and museum curators tend to emphasize "wall power" more than librarians where exhibitions are at issue. But these differences are not insurmountable, and in a digital environment-where it sometimes seems that a lot of the foundation and other negotiable monies are increasingly meant for electronic projects rather than for more traditional activities like collecting and cataloging - it can only make sense for institutions that exist by virtue not of code but of tangible objects to learn to respect and value each other.

Gerald has captured a crucial, defining difference between museums and libraries with his suggestion that museums are about programs and libraries are about systems. Yet I believe that even distinctions of such a fundamental nature may be blurring if they have not already been erased. One can trace that blurring over the last half century or more as museums have become increasingly scholarly in their catalogues and record-keeping and libraries have become more cognizant of the value of interpreting their holdings to wider publics through exhibitions and catalogues. Libraries like the Lilly at Indiana University or the Fisher at the University of Toronto are perceptibly straying into the conventional territory of the museum. They do remarkable exhibitions with remarkable catalogues, after all; and if the objects they focus on only infrequently include paintings and sculpture, it is not easy to extend that short list of differences. Museums, for their part, are less averse now to book exhibitions than was once the case. Cindy Burlingham of the Armand 
Hammer Museum of UCLA (with whom I worked on The World from Here exhibit a few years ago), has attested to the resistance she met from colleagues when she proposed an earlier exhibition there on the subject of children's books, a show they called Picturing Childhood: Illustrated Children's Books from University of California Collections, 1550-1990. That exhibition was remarkably successful with critics and audiences alike, and its popularity made our proposal to mount The World from Here at the Hammer substantially more welcomed than might have been the case otherwise.

In light of the success of The World from Here, I have to disagree respectfully with Gerald's contention that the book as an exhibitable object is a failure. It is true that not all books are comely, even - perhaps especially - some of the most famous and influential. Picture in your mind for a moment a copy of the first edition of Alberti's De re aedificatoria, or Pride and Prejudice, or Darwin's Origin of Species, or even Ulysses, and you get the idea. Some books are, of course, as visually compelling as a Gaugin painting or a David Smith sculpture. Books from the fine press or book arts traditions are contrived to be aesthetically compelling from the start. Yet exhibitability is not merely relative, it is contextual; and while museums everywhere are cognizant of the limited amount of text that visitors are willing to read these days before they blank out or move on-an undeniable challenge in what pessimists increasingly regard as a postliterate age-interpretation nevertheless remains one of a museum's mandates. Books and manuscripts, too, can be interpreted to bring them alive, even in glass cases. All of us who work with books and archives will have experienced the shock and awe that the average library visitor frequently evinces when shown an old book of some fame. They are essentially surprised that one can see and touch such things. That surprise needs only to be artificially stimulated with museum techniques of display for books to work in exhibitions. I would also venture that, as younger generations become more and more accustomed to everything being digital—you can already read the Principia or walk the Appian Way or leaf through the only surviving manuscript of Beowulf online-people generally will hunger more, not less, for real cultural objects, and the kind of totemic value that an actual copy of the first folio of Shakespeare has (a common rare book, after all) will increase, not fade away. That fact will, in and of itself, make such objects more exhibitable. Gerald is right to remind us of the emotions we feel when we ardently grasp an old book or a file of letters released from a Hollinger lockup. Museums, on the other hand, typically are not in the business of delivering their stuff into anybody's hands. And that, perhaps, is an irrefutable difference among the institutions under discussion here.

Both museums and libraries have traditionally approached collecting with diversity and hybridity in mind, as Gerald has already remarked. The Cotton manuscripts 
were one of the foundation collections at the British Museum when it was established in the middle of the eighteenth century, and 175 years later Henry Huntington's encyclopedic vision of a library included manuscripts, drawings, paintings, sculpture, and so on. Even though it is true that the marriage of books and museum objects that formed the British Museum went through divorce proceedings in 1973, it seems to me an irrefutable fact that, in general, the role of museums and libraries/archives is coalescing in the digital age.

Does this mean that we should all promiscuously collect the other's traditional objects? I think so, with the proviso that, in an urban context where there are multiple institutions, there will be some deliberate and coordinated collecting specialization — not because all incunables by definition should be in a library and all Modigliani drawings should by definition be in a Prints and Drawings Room within a museum, but more because of established strengths and limited resources. The ultimate purposes of such collecting - preserving the cultural heritage, showing it to a broad public, and making it accessible for more intimate study and researchought to be the same, for practical as well as more idealistic reasons. After all, these purposes mark one of the crucial differences between institutional and private collecting.

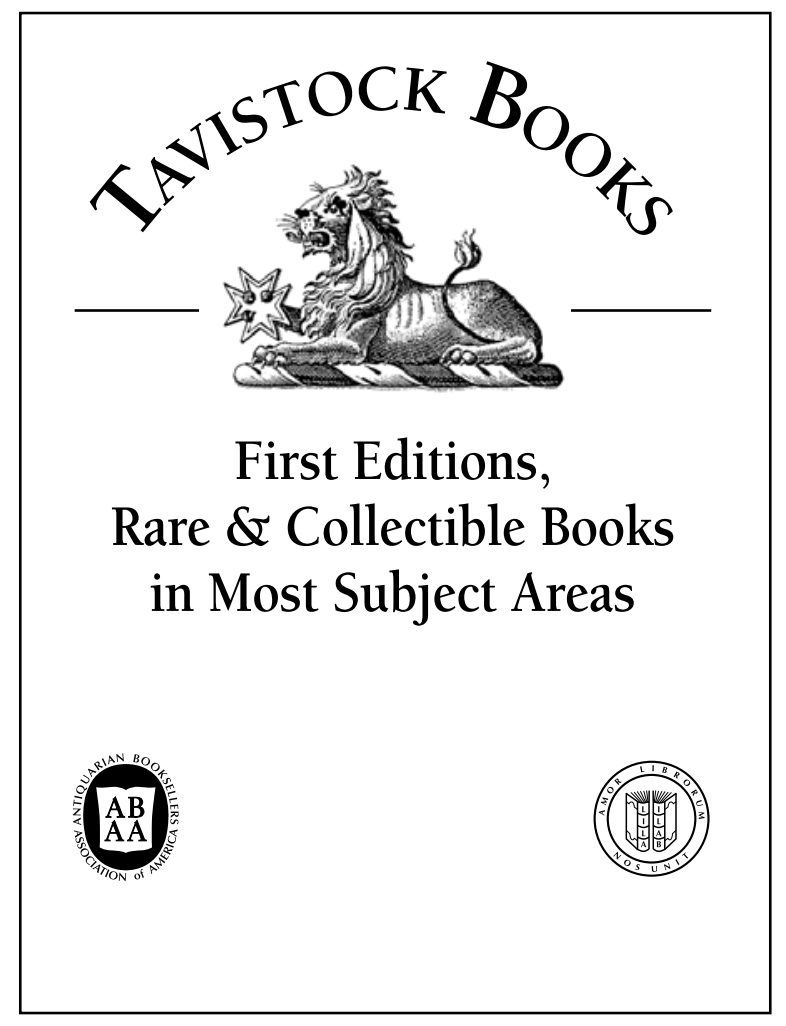

